\title{
A dialética do conceito de exclusão/inclusão social
}

\author{
Maria Izabel Sanches Costa \\ Aurea Maria Zöllner lanni
}

\section{SciELO Books / SciELO Livros / SciELO Libros}

COSTA, M.I.S., and IANNI, A.M.Z. A dialética do conceito de exclusão/inclusão social. In:

Individualização, cidadania e inclusão na sociedade contemporânea: uma análise teórica [online]. São Bernardo do Campo, SP: Editora UFABC, 2018, pp. 75-101. ISBN: 978-85-68576-95-3. https://doi.org/10.7476/9788568576953.0004.

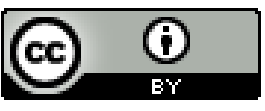

All the contents of this work, except where otherwise noted, is licensed under a Creative Commons Attribution 4.0 International license.

Todo o conteúdo deste trabalho, exceto quando houver ressalva, é publicado sob a licença Creative Commons Atribição 4.0.

Todo el contenido de esta obra, excepto donde se indique lo contrario, está bajo licencia de la licencia $\underline{\text { Creative }}$ Commons Reconocimento 4.0. 


\section{A DIALÉTICA DO CONCETTO DE EXCLUSÃO INCLUSÃOSOCAL}

Este capítulo está voltado a uma análise sobre o conceito Le inclusão e exclusão social e de como essas duas categorias estão intrinsecamente relacionadas. A importância da compreensão de ambas justifica-se ao afirmarmos que a inclusão social efetiva-se no combate às dimensões da exclusão. Isso quer dizer que, a priori, é necessário compreender o que causou a exclusão antes de criaremse estratégias de inclusão.

Segundo Scarcelli (2011, p. 30), inclusão “[...] refere-se ao ato ou efeito de incluir". No dicionário Aurélio (2010), o termo inclusão aparece como "abranger, compreender, conter, envolver, pôr ou estar dentro, inserir num ou fazer parte de um grupo". Associada ao adjetivo social "que diz respeito à sociedade", também segundo o dicionário, a inclusão social pode ser entendida como um ato de inserir algo na sociedade para que, assim, possa fazer parte dela. Esse conceito é extremamente vinculado ao seu oposto, a exclusão social, ou seja, para entender como funciona o processo de inclusão, faz-se necessário compreender como deu-se a exclusão. 
0 conceito de exclusão social é relativamente recente na literatura e teve como berço a Europa, na segunda metade do século XX (ZIONI, 2006). Lenoir (1989), em Les Exclus, publicado primeiramente em 1974, foi um marco para a compreensão do conceito vinculado ao sentido de inadaptação social. A exclusão é um fenômeno irredutivelmente social e sua origem a aproxima da compreensão de disfunção ${ }^{6}$ da própria sociedade. 0 autor chamou a atenção para o fato de que uma economia em expansão tende para a exclusão dos grupos que apresentam uma diferenciação física, psíquica e social.

De acordo com Escorel (2009), o processo de pauperização na França, na década de 1970, começou a atingir os grupos não considerados tradicionalmente marginalizados e que até então usufruíam dos benefícios do desenvolvimento econômico. "A exclusão social passou a ser usada para denominar o fenômeno integrante de uma 'nova questão social', problemática específica do final do século XX cujo núcleo duro foi identificado na crise do assalariamento como mecanismo de inserção social" (ESCOREL, 2009, p. 1).

Dupas (1998, p. 123) evidencia que

[...] a discussão sobre exclusão social apareceu na esteira do crescimento dos sem-teto e da pobreza urbana, da falta de perspectiva decorrente de desemprego de longo prazo, da falta de acesso a empregos e rendas por parte de minorias étnicas e imigrantes, da natureza crescentemente precária dos empregos disponíveis e da dificuldade que os jovens passaram a ter para ingressar no mercado de trabalho.

\footnotetext{
${ }^{6}$ Entende-se aqui por disfunção da sociedade o ato de divisão, dissociação, separação e segregação de membros desse grupo social.
} 
Segundo o autor, esse efeito foi, em parte, em decorrência do processo de globalização acentuado nos anos 1980.

Em consonância aos autores anteriores, Campos et al (2003) afirmam que a emergência de estudos sobre o conceito de exclusão social é consequência do agravamento dos processos excludentes da década de $1970 \mathrm{em}$ diante, nos países capitalistas, a partir da adoção de políticas macroeconômicas neoliberais e a emergência de inovações tecnológicas.

Segundo Escorel (2009), a noção de exclusão como o processo social progride a partir de trajetórias com rupturas de vínculos sociais frágeis. Dessa forma, a autora traça um paralelo entre a exclusão e a desvinculação, e deixa claro que esse fenômeno percorre diversos âmbitos sociais (o econômico, o familiar, o biológico, o cultural, o psicológico etc.). 0 conceito define processos sociais de discriminação, estigmatização e vulnerabilidade.

Para Wanderley (2001), a exclusão social é um processo de privação que inclui a pobreza, a discriminação, a subalternidade, a iniquidade e diversas formas de desigualdades. Em suma, a exclusão social não começa e termina apenas na pobreza, pois são múltiplos os fatores que corroboram para que ela aconteça.

Seguindo a linha de raciocínio de Escorel (2009) e de Wanderley (2001), Déchamps (1998 apud ESTIVILL, 2003, p. 47, grifo do autor) mostra-nos a existência de três dimensões da exclusão social - a econômica, a social e a simbólica.

[...] a dimensão econômica da exclusão implica a sucessiva ausência do mundo produtivo e do consumo, a sua dimensão social compreende a perda da sociabilidade primária e secundária, e a sua 
dimensão simbólica é definida pelos comportamentos e valores comuns, assim como pelas representações que tendem a classificar socialmente as pessoas (dé-chéance, incompetência, mediocridade, identidade negativa).

O exemplo da pobreza, utilizado por Sposati (1999), ratifica as dimensões citadas por Déchamps (1998 apud ESTIVILL, 2003). A pobreza absoluta ou relativa (uma questão econômica) pode ser somada a questões de discriminação e estigma, seja pela condição econômica, de gênero, raça, orientação sexual etc. À exclusão social, nesse caso, soma-se a privação econômica, a discriminação e a fragilidade dos vínculos sociais.

Afirma Kowarick (2003) que há uma imprecisão no termo exclusão e que ele é usado de forma ampla e escorregadia, sendo, algumas vezes, confundido com vulnerabilidade. Segundo o autor, o termo exclusão traz a ideia de não ser admitido ou mesmo de ser repelido, expulso e banido de um dado grupo. Ele aproxima o conceito à ideia de destituição de direitos ou de perda do direito de ter direitos.

Em suma, exclusão aponta uma condição de desposessão de direitos, chegando a atingir casos extremos de extermínio em massa, cujos exemplos podem ser encontrados entre os considerados heréticos pela Santa Inquisição, os judeus e ciganos na Alemanha nazista ou, mais recentemente, as vítimas da atrocidade em Kosovo. (KOWARICK, 2003, p. 22).

Resumindo, para o autor, exclusão quer dizer banimento e/ou isolamento, o que difere do que comumente 
chamam de vulnerabilidade. Indivíduos vulneráveis têm vínculos sociais e econômicos precários.

Castel (1994; 2000), por sua vez, não utiliza o conceito de exclusão por considerá-lo atualmente um conceito mala, ou seja, é tão amplo que deixa de evidenciar os diferentes processos que atravessam a sociedade contemporânea. 0 autor propõe o uso do conceito de desfiliação para referir-se a um alto grau de vulnerabilidade social. Para o autor, não se pode considerar que exclusão seja uma condição de ausência de algo (seja de renda, alimento, moradia, educação, saúde etc.), mas, sim, a composição de três eixos: precarização do trabalho, precarização da sociabilidade primária ${ }^{7}$ e negação do status social. A relação entre os eixos cria quatro estados entre a integração e a desfiliação:

[...] zona de integração (trabalho estável e forte inserção relacional, que sempre estão juntos), a zona de vulnerabilidade (trabalho precário e fragilidade dos apoios relacionais) e a zona de marginalidade, que prefiro chamar de zona de desfiliação para marcar nitidamente a amplitude do duplo processo de desligamento: ausência de trabalho e isolamento relacional [...] tratamento dispensado à indigência inválida define uma quarta zona, a zona da assistência. (CASTEL, 1997, p. 23-24, grifo do autor).

\footnotetext{
7 O sistema de proteção social para Castel (1998a) é composto de dois modelos: sociabilidade primária e sociabilidade secundária. A primária é regida pelos vínculos estabelecidos na relação de proximidade e pertencimento, ou seja, uma rede sem a mediação de uma instituição específica. Dentre eles, encontram-se a família, a vizinhança, os amigos etc. A secundária emerge com a fragilidade da primária, quando a sociedade torna-se mais complexa e ocorre um entrelaçamento das redes que compõem a primeira. Nela, torna-se necessário um atendimento mais sofisticado e institucional. É nesse momento que emerge a proteção social institucionalizada.
} 
Como é possível perceber, Castel (1997, p.31) deixa claro que os pontos centrais para a desfiliação são o trabalho e as relações sociais. Desfiliação, assim, segundo o autor, pode ser compreendida pela "[...] conjunção perda de trabalho-isolamento relacional".

Em relação ao trabalho, o autor analisa esse eixo segundo a queda da sociedade salarial ${ }^{8}$. Em seu texto As metamorfoses da questão social, o autor evidencia não só a precarização do trabalho e a perda das garantias trabalhistas na sociedade contemporânea, mas também como esse processo provoca um estado de vulnerabilidade social.

No que se refere à rede de sociabilidade primária, Castel (1994) considera-a como sendo a de uma rede de relações sociais, responsável pelo suporte e solidariedade (família, amigos, vizinhos, colegas de trabalho etc.) que não se fundamenta nas instituições formais do Estado. Essa rede pode ser compreendida como uma rede de laços entre os membros que a compõem e que nela criam sentimentos de pertencimento. Em meio a esse grupo, são reproduzidos costumes e tradições, os papéis sociais são veiculados e, assim, uma existência social é reproduzida internamente. Em suma, as relações sociais são um elemento constitutivo do que o autor denomina de proteção

\footnotetext{
8 O modelo de sociedade característico no século XX é construído ao redor do trabalho e é denominado por Castel (1998) como a sociedade salarial industrial. Tal sociedade é caracterizada por sua organização em torno de uma economia de mercado, que compra e vende trabalho-mercadoria, regulada por um direito do trabalho que estabelece as relações laborais entre o capital e o trabalho e que tem em seu bojo um Estado de bem-estar social construído no ideal da democracia burguesa. Para Castel (1998), as legislações trabalhistas e políticas sociais que instituíram a seguridade social (direito à aposentadoria, seguro desemprego e assistência à saúde) são as materializações dos suportes sociais garantidos por instituições do Estado nas quais se estruturaram as relações de trabalho na sociedade salarial.
} 
aproximada. Entretanto, o estado de desfiliação para Castel (1998a) é formado pela perda do trabalho e da sociabilidade primária, porque tais perdas acarretam a privação econômica e a fragilidade de laços sociais.

Além desses dois quesitos, para Castel (1998a; 1998b), pode ocorrer o processo de desfiliação, quando há a negação das normas estabelecidas pela sociedade e, assim, a ruptura com o status ou a posição de um indivíduo pertencente a esse grupo. 0 autor utiliza a história de Tristão e Isolda (CASTEL, 1998b) para exemplificar essa questão. São os casos de indivíduos desfiliados pela negação das normas impostas ou mesmo pela falta de oportunidade de acesso a elas, tendo, assim, o seu pertencimento negado.

No Brasil, o conceito de exclusão social nas ciências humanas aparece quase sempre relacionado à desigualdade de renda. A exclusão social configura-se como marca inquestionável do desenvolvimento capitalista no país. Véras (2001) ressalta que os processos sociais excludentes estão presentes desde os tempos coloniais (população indígena e negra), contudo, tornaram-se mais intensos durante o período militar. Para a autora, a exclusão é a consequência do desejo da burguesia de subordinar o social ao econômico. 0 resultado é o controle dos dominados por meio da lógica de poder dominantes-dominados.

Campos et al (2003) aponta a existência de duas formas de desigualdade no país: a velha e a nova exclusão social. A velha exclusão manifesta-se devido aos baixos níveis de escolaridade, à falta de acesso a bens e serviços básicos, ao trato com as diferenças raciais e étnicas etc. Considerando-se as transformações que ocorreram nos países emergentes, principalmente a partir da segunda metade do século XX, novas formas de exclusão surgem 
sem que a primeira tenha sido superada completamente. Para o autor, no Brasil, as novas formas de exclusão, que convivem com as velhas, podem ser identificadas no número de moradores em situação de rua, na precarização do mundo do trabalho, no baixo nível de renda, no advento da insegurança vivenciada nas diversas formas de violência etc.

Embora diversos indicadores sociais - como índice de analfabetismo, renda, acesso à saúde pública, saneamento e moradia - indiquem que a velha exclusão social no Brasil tenha melhorado desde os anos 1980, ela não foi superada. É preciso verificar que o processo de individualização e o consumo, dentre outros fatores, acirram o processo da nova exclusão social.

Véras (2001) afirma que as condições desfavoráveis de tais contingentes excluídos contribuíram para gerar sentimento de hostilidade, desconfiança e medo por parte dos demais segmentos, fazendo com que aumentasse a demanda por políticas de segurança e repressão, agravando ainda mais o processo de exclusão. Ademais, a autora cita a proliferação de loteamentos fechados, condomínios horizontais (prédios), shopping centers com câmeras de vigilâncias, seguranças nas portas e controle de acesso como consequências desse processo e formas de segregação.

No campo da saúde, a Organização Internacional do Trabalho (OIT) e a Organização Pan-Americana da Saúde (OPS) definem a exclusão social como um processo multidimensional que abarca a ausência tanto de recursos, quanto de oportunidades e de pertencimento. Como já apontado, por pertencimento entende-se a construção de laços sociais que permite aos indivíduos fazer parte de uma rede social (OIT, OPS, 1999). 
É possível perceber, portanto, por meio da definição de exclusão social dos autores mencionados anteriormente, que esse conceito é multidimensional, ou seja, engloba várias questões. Segundo Sawaia (2001), esse é um conceito que permite usar diversos repertórios, desde a concepção de desigualdade, como sendo resultante de uma deficiência ou inadaptação individual, à falta de algo, até mesmo como condição de uma injustiça social. De acordo com a autora, a sociedade exclui para incluir. Essa é uma dialética da própria sociedade.

A sociedade exclui para incluir e essa transmutação é condição da ordem social desigual, o que implica o caráter ilusório da inclusão. Todos estamos inseridos de algum modo, nem sempre digno, no circuito reprodutivo das atividades econômicas, sendo a grande maioria da humanidade inserida através da insuficiência e das privações, que se desdobram para fora do econômico. (SAWAIA, 2001, p. 8).

Para a autora, essa dialética dos processos de inclusão e exclusão não é uma falha do capitalismo, mas, sim, um processo intrínseco da sua lógica, que se manifesta nas contradições da desigualdade e da necessidade de uma legitimação social. A dialética inclusão/exclusão demonstra que essa noção deve ser compreendida tanto como um processo que pode estar em constante movimento - o indivíduo/grupo pode estar excluído em um fator e incluído em outro -, quanto estando relacionada com os modos de sociabilidade e valores sociais (SAWAIA, 2001).

Nesse contexto, a inclusão é parte constitutiva da exclusão, isto é, não é uma coisa ou um estado, mas, sim, um processo que envolve o indivíduo perante a sociedade. 
É um produto do funcionamento do sistema (SAWAIA, 2001). Seus mecanismos estão inseridos nas estratégicas histórias de manutenção de uma ordem social perversa, no estabelecimento de formas de desigualdade, nos processos de concentração de riqueza. 0 excluído é parte integrante de uma sociedade, de forma a sustentar uma dada ordem social.

\section{O CONCEITO DE EXCLUSÃOSOCCAL}

Nossa definição se aproximará de alguns pressupostos apresentados por Escorel (2009), Wanderley (2001) e Castel (1998a), ao afirmarmos que a exclusão é um estado de vulnerabilidade em níveis de maior ou menor intensidade e que percorre de diversos âmbitos sociais: o econômico, o social, o biológico e o psicológico. A exclusão social não se esgota na desigualdade social, pois são múltiplos os fatores que corroboram para que ela aconteça. Assim, a exclusão pode e deve ser compreendida como um processo pluridimensional que segrega e inferioriza um indivíduo ou um grupo perante sua comunidade e seu território. Sua base de segregação está nos valores dominantes da sociedade.

Para nossa definição, utilizaremos três dimensões que consideramos ser os pilares desencadeadores do processo de exclusão social. Para tal, emprestaremos dois eixos apresentados por Castel (1998a): precarização do trabalho e precarização da sociabilidade primária. Acrescentaremos mais um eixo, o do estigma. Em suma, partimos da definição da exclusão social como processo de vulnerabilidade composto de três dimensões: 
precarização do trabalho, precarização da sociabilidade primária e estigma.

\section{a) Precarização do trabalho}

Bauman (2001), Beck (2011) e Castel (1998a) evidenciam a centralidade do trabalho como meio para a inserção social do indivíduo na modernidade. Outros autores, como Clavel (2012), em consonância a Bauman (2001), ao analisar a exclusão social, também consideram que o trabalho é parte constitutiva da construção de uma identidade coletiva e individual. Clavel (2012) afirma que a ausência do trabalho pode produzir a perda do sentimento de pertencimento a um grupo, a uma classe, a um sindicato.

Paugam (2006) sinaliza que a ausência de estabilidade no emprego gera no indivíduo sentimentos de culpa e de falta de perspectiva de vida pela perda de sua identidade de trabalhador. 0 autor enfatiza também os sentimentos de vergonha e apatia dos desempregados de longo período, fazendo com que se afastem do convívio social com os amigos e mesmo com os familiares. Chama ainda a atenção para a atual instabilidade no mercado de trabalho, que gera formas de contratação precárias e acentua a rejeição dos trabalhadores menos qualificados.

É evidente a importância da dimensão do trabalho no que se refere à inclusão do indivíduo na sociedade. Entretanto, cabe aqui fazer uma reflexão sobre os impactos das transformações que a categoria trabalho tem sofrido na sociedade contemporânea.

Ao examinar as transformações no mundo do trabalho ante a internacionalização do mercado decorrente 
da globalização na sociedade contemporânea, Castel (1998a) identifica a ocorrência de dois tipos de redução de custos em face dos requisitos da flexibilização: minimização do preço da força de trabalho e maximização de sua eficácia produtiva. Tais processos produzem o desemprego, a precarização e a individualização dos comportamentos no trabalho. A precarização decorre do desenvolvimento tecnológico da evolução do capitalismo, e a flexibilização, por sua vez, provoca a individualização dos comportamentos no trabalho.

Tanto Bauman (2001) quanto Beck (2011) estão alinhados à análise de Castel (1998a), ao partirem da certeza sobre o fim do emprego industrial no cerne das características da sociedade moderna. Beck (2011) analisa a questão do trabalho a partir da noção da sociedade de risco. 0 autor ressalta que, quanto mais as relações, as condições e o mercado são desregulamentados e flexibilizados, mais rapidamente, e com eficiência, a sociedade do trabalho torna-se sociedade de risco.

É no contexto da individualização contemporânea que Beck (2011) analisa a despadronização do trabalho assalariado, da formação e da ocupação, afirmando que o trabalho flexível e a subocupação substituem a ocupação integral. 0 direito, o local e o tempo que eram os pilares desse mundo do trabalho tradicional não são mais considerados como tal. Para o autor, nesse contexto de incerteza, os riscos psíquicos e de saúde são privatizados para o próprio trabalhador, sendo assim, cada trabalhador é responsabilizado individualmente. 0 indivíduo deve autogerir-se, inclusive, em aspectos relativos à proteção social e às condições de trabalho. A grande característica do trabalhador contemporâneo é o fato de constituir-se em 
uma espécie de multiuso, de modo que sua existência é marcada pela insegurança constante.

Assim como em Beck (2011), para Bauman (2001), os trabalhadores, passam a conviver com a incerteza do trabalho flexível e sem a possibilidade vitalícia de trabalho, que foram extintas junto com as certezas do trabalho na era do capitalismo industrial. Considera Bauman (2001) que a incerteza sempre acompanhou o trabalhador, mesmo na fase anterior da sociedade, mas na sociedade contemporânea adquire o caráter de poderosa força individualizadora que, ao contrário de unir, divide. Indica também que, na atualidade, ocorre a perda da capacidade de coesão, historicamente atribuída ao trabalho, e da construção da identidade, a partir de classes sociais coesas. 0 trabalho de longa duração, aqui, é também substituído pela volatilidade do mercado da força de trabalho.

Segundo Bauman (2001), a reestruturação produtiva e industrial na sociedade contemporânea decorre de um processo que compatibiliza mudanças organizacionais, redefinições de papéis dos Estados nacionais, centralidade do capital financeiro, tecnologias informatizadas e a crescente necessidade de garantia do lucro. Esse novo modelo rompe com o do fordismo e tem por base a flexibilização do trabalho e a necessidade de um trabalhador polivalente, que seja capaz de lidar com as mais diversas tecnologias, de estar disponível 24 horas, de aprender novas formas de gestão que enfocam a subjetividade, de não ser mais um empregado, mas, sim, um colaborador, de redefinir a relação de solidariedade operária por meio da individualização do salário e as relações entre pares por clientes. 0 trabalhador deve ser um indivíduo 
empreendedor, estar sempre capacitado e ser responsabilizado por suas escolhas e sua carreira.

Castells (1999b), em conformidade com os autores anteriores, afirma que, com o advento do fim da sociedade industrial, surge um novo sistema de produção. Ademais, declara que, nesse novo sistema, a produtividade e a competitividade constituem os seus principais processos, nos quais a primeira origina-se da inovação e a segunda da flexibilização.

Portanto, empresas, regiões, países, unidades econômicas de todas as espécies preparam suas relações de produção para maximizar a inovação e a flexibilidade. A tecnologia da informação e a capacidade cultural de utilizá-la são fundamentais no desempenho da nova função da produção. Além disso, um novo tipo de organização e administração, com vistas à adaptabilidade e coordenação simultâneas, tornam-se a base do sistema operacional mais efetivo, exemplificado pelo que rotulei de empresa em rede. (CASTELLS, 1999b, p. 417).

Nesse novo contexto, a mão de obra é redefinida, emergindo daí dois tipos de trabalhadores denominados pelo autor como mão de obra genérica e mão de obra autoprogramável. As características primordiais que diferenciam os dois trabalhadores são a capacidade educacional e a incorporação de informação. Essas características, empregadas à mão de obra autoprogramável, permitem ao trabalhador a "[...] capacidade para uma redefinição constante das especialidades necessárias à determinada tarefa [...]" (idem). Em contrapartida, a mão de obra genérica, sem acesso à educação, "[...] recebe determinada tarefa sem nenhum recurso de reprogramação, e não se 
pressupõe a incorporação de informação e conhecimentos além da capacidade de receber e executar sinais [...]" (idem). Dessa maneira, os trabalhadores podem e são facilmente substituídos por máquinas ou outros trabalhadores com custos mais baixos.

Embora, no conjunto, sejam imprescindíveis, ao processo produtivo, individualmente esses trabalhadores são dispensáveis, pois o valor agregado de cada um deles representa uma pequena fração do que é gerado pela e para a organização. Máquinas e mão-de-obra genérica de várias origens e locais coabitam os mesmos circuitos subservientes do sistema de produção. (ibidem, p. 418).

Frente a um mundo globalizado, tecnológico, rápido, informacional e individualizado, o trabalhador vê-se imerso na necessidade, cada vez maior, de qualificar-se, reinventar-se e atualizar-se. Logicamente, um sem número desses trabalhadores não consegue acompanhar a nova necessidade do mercado. Frente ao processo de individualização radicalizada, a culpa recai sobre o próprio trabalhador que "[...] não consegue acompanhar a constante e necessária atualização profissional. Com isso, ficam para trás na rodada de 'enxugamento' dessa camada intermediária, que constituiu a força das sociedades capitalistas avançadas durante a era industrial e agora se encolhe cada vez mais" (CASTELLS, 1999b, p. 421).

Segundo Castells (1999b), os trabalhadores genéricos são levados a circular por vários empregos, na maioria das vezes informais, sem vínculos e inseguros. Essa instabilidade dificulta ainda mais o acesso à educação, fazendo com que o trabalhador entre num ciclo que não mais consegue sair. 
A perda da relação estável a um nível mais alto de incidência de crises profundas na vida familiar: perda temporária de emprego, crises pessoais, doenças, vícios em drogas/álcool, perda da empregabilidade, perda de bens, perda de crédito. Muitas dessas crises ligam-se entre si, provocando a espiral descendente da exclusão social rumo ao que chamei de 'os buracos negros do capitalismo informacional'. (CASTELLS, 1999b, p. 421).

Esse novo contexto do mercado de trabalho contemporâneo radicaliza ainda mais a desigualdade social existente, privilegiando, obviamente, quem tem a possibilidade de qualificar-se de forma constante. E é ainda mais perverso ao responsabilizar o indivíduo por sua dificuldade de inserção ao trabalho (BAUMAN, 2001; BECK, 2011).

A despeito disso, ressaltam-se os dois aspectos dessa situação: da parte do trabalhador, a precarização das relações de trabalho, que gera desemprego, terceirização, subcontratação etc.; do lado do empregador, o resultado manifesta-se em lucro e acumulação.

Os maiores consensos entre os quatro autores Castells (1999b), Bauman (2001), Beck (2011) e Castel (1998a) - estão na evidente precarização do mundo do trabalho contemporâneo, na preocupação com a responsabilização do indivíduo e de como cada um deve aprender a conviver com suas ansiedades e preocupações de forma isolada.

Em suma, o trabalho contemporâneo caracteriza-se majoritariamente por contratos não regulamentados, por tempo parcial, pelo emprego por tempo determinado, pela subcontratação, pelas chamadas economias informais que englobam o trabalho autônomo. Essa é mais uma das características do processo de individualização refletida 
agora no mundo do trabalho. Seu produto é o aumento da precarização das relações de trabalho, o que não significa que na sociedade atual o trabalho perca sua centralidade. Ao contrário, ele se mantém como um dos vetores importantes na organização da sociedade, nas relações sociais entre indivíduos e grupo, mas reconfigura-se de acordo com as características atuais (BAUMAN, 2001; CASTEL, 1998; CASTELLS, 1999).

Isso quer dizer que o trabalho tem sua importância enfraquecida na construção da identidade individual e coletiva (quando falamos de classe), privatiza os riscos e traz um sentimento ainda maior de incerteza e responsabilização individual. No lugar da proteção assegurada pelo trabalho, prevalece, hoje, o discurso liberal do empreendedorismo, que direciona com mais força a ideia de responsabilização do indivíduo sobre seu destino e êxito em sua vida profissional. 0 processo de individualização fragiliza os vínculos e suportes de proteção do trabalhador (BECK, 2011). Tais transformações impactam negativamente na forma com que essa categoria contribui para a inserção social dos indivíduos na sociedade contemporânea.

\section{b) Precarização da sociabilidade primária}

A sociabilidade primária para Castel (1998a) é regida pelos vínculos estabelecidos na relação de proximidade, pertencimento e interdependência, ou seja, uma rede sem a mediação de uma instituição - Estado e políticas públicas. São os vínculos com a família, vizinhança, amigos etc. São essas as relações que garantem o suporte social necessário para o indivíduo sentir-se parte integrante da sociedade. Partiremos dessa definição. 
Na sociedade moderna, os laços sociais mais fortes estavam centrados na família e na classe social; em suma, laços comunitários, um por sangue e outro pelo sentimento de pertencimento a um grupo (e.g. burguesia/proletariado). Esses dois pilares eram constitutivos da inserção social, na construção da identidade e no suporte social do indivíduo no mundo moderno. Uma das consequências para o processo de desfiliação, segundo Castel (1998a), é a perda dos suportes sociais. Como já analisado no primeiro capítulo, os processos de individualização e de consumo influenciaram e flexibilizaram tais pilares, de forma que alteraram significativamente os modos de sociabilidade e a criação de laços sociais na sociedade contemporânea. Os impactos que se pretende analisar aqui são: a fragilidade dos laços comunitários e as transformações na categoria família.

Lipovetsky (2005a) afirma que, a partir de um processo narcísico, no qual o eu torna-se o objeto de investimento e o indivíduo vê-se na busca constante pela realização do seu ego, os laços sociais tornam-se cada vez mais frágeis na sociedade contemporânea. Consoante esse autor, para Castel (1998a), o processo de individualização faz com que o indivíduo feche-se e esteja voltado para si mesmo. Tal como Lipovetsky (2005a), ele também lança mão da lenda de Narciso para constatar que, ao voltar-se para dentro de si, o indivíduo tende a confundir-se com sua própria imagem.

Sob essa mesma perspectiva, Bauman (2004) demonstra que a fragilidade dos laços humanos na sociedade contemporânea está carregada de sentimentos de insegurança. Isso faz com que os indivíduos relacionem-se, mutuamente, com desconfiança e temeridade quanto ao estreitamento e prolongamento de vínculos. 0 que de fato 
ocorre é que, devido ao medo de assumir responsabilidades por parcerias mais prolongadas, tais relações são percebidas como ameaças à individualidade.

Nesse cenário, e com o surgimento da internet 2.0, emergem as relações virtuais que se caracterizam pela virtualidade, sendo consideradas mais superficiais no sentido do pressuposto de que são interações frágeis, que não promovem contato físico e dificultam a intimidade. Tais relações, segundo Bauman (2004), promovem a ilusão da criação de laços afetivos, mas elas podem ser desfeitas com a mesma rapidez com que foram construídas.

Bauman (2001, p. 114) aponta o surgimento de uma nova categoria de sociabilidade contemporânea, a que é utilizada nos "[...] espaços públicos, mas não civis". Para o autor, há um esvaziamento do espaço público e, consequentemente, um rebaixamento da integração política, na qual as preocupações e as motivações sociais estão limitadas aos interesses individuais e privados. Em suma, se há uma interação nos espaços públicos, essa dificilmente se dá por uma questão coletiva ou cívica.

É nesse sentido que, para o autor, há na atualidade um aniquilamento do conceito de coisa pública, porque a individualização produzida na contemporaneidade neoliberal leva o sujeito a não ver qualquer sentido na sociedade da qual faz parte. No dizer de Castel (1998a), isso é percebido pela falta da recusa em não se engajar por medo de assumir responsabilidades e de construir laços sociais mais duradouros.

Ainda citando Bauman (2004), ele faz uma crítica ao mercado que se apropria de ideias e sentimentos com o intuito de estimular o consumo. 0 autor enfatiza a apropriação dos laços humanos pelo mercado, que os transforma 
em mercadorias a serem vendidas em suas prateleiras, como qualquer outro produto.

Segundo o autor, o mercado procura transformar os laços humanos em produtos postos à venda, tornando-os objetos que podem ser comprados.

Onde há chance de lucro - e os especialistas em marketing levam sua engenhosidade ao limite para indicar maneiras de adquirir em lojas a solidariedade, o sorriso amigo, o convívio ou a ajuda no momento de necessidade. [...] Em versão à venda, os vínculos se transformam em mercadorias, ou seja, são transformados para outro domínio, governados pelo mercado, e deixam de ser os tipos de vínculos capazes de satisfazer a necessidade de convívio e que só nesta podem ser concebidos e mantidos vivos. (BAUMAN, 2004, p. 91).

Ao transformar seres humanos e relacionamentos em produtos de consumo, os agenciadores capitalistas proporcionam a ampliação da precarização dos laços sociais, transformando-os segundo a lógica de mercado, que impõe uma velocidade cada vez maior no uso dos objetos e no seu descarte - imperativo da substituição frenética dos modelos mais novos disponíveis. Os laços humanos passam, então, a adquirir essa mesma característica, a de objetos descartáveis.

O desvanecimento das habilidades de solidariedade é reforçado e acelerado pela tendência, inspirada no estilo de vida consumista, a tratar os outros seres humanos como objeto de consumo e julgá-los segundo o padrão desses objetos, pelo volume de prazer que provavelmente oferecem e em termos de seu 'valor monetário' [...] A solidariedade humana é a primeira baixa causada pelo triunfo do mercado consumidor. (BAUMAN, 2004, p. 96). 
As relações humanas sofrem, assim, uma mutação, transformando-se em objetos de consumo e, nessa nova condição, assumem novos atributos: utilidade, descartabilidade, durabilidade. 0 relacionamento social converte-se em uma espécie de troca, ou seja, os sujeitos tomam atitudes a partir do que receberam ou com base no que receberão e esquecem-se dos vínculos de solidariedade e amizade, transformando os laços afetivos em uma questão de interesse e troca. É a busca por gratificação instantânea e felicidade individual. Os indivíduos ficam imersos nas fantasias do consumo hedonista, não se preocupando com nada mais além do prazer momentâneo.

Em meio a esse cenário, a família, tal como ela se consolida na modernidade, também sofre transformações. Castells (2000) afirma que o modelo familiar patriarcal entrou em crise e, consequentemente, houve o crescimento de famílias chefiadas por mulheres, bem como a de outras configurações familiares diferentes do modelo patriarcal. É nesse sentido que Perucchi e Beirão (2007, p. 66) analisam: "O modelo patriarcal de família, caracterizado pelo arranjo composto por pai, mãe e filhos que convivem sob a égide da autoridade do primeiro sobre os demais, está em crise". Tal crise vem em decorrência das lutas históricas de emancipação feminina e de conscientização da mulher em um contexto de transformação no mercado de trabalho.

As transformações da categoria família são movidas por vários processos que estão vinculados, dentre eles: 0 processo de individualização - já apresentado -, a emancipação da mulher no mercado de trabalho, o envelhecimento da população, a diminuição da taxa de natalidade e novos formatos familiares. É importante ressaltar que o processo de individualização está intimamente vinculado 
aos demais, ou melhor, ele é uma das causas dos demais processos.

Relativamente à emancipação da mulher no mercado de trabalho, segundo Silva et. al. (2005), nos últimos 50 anos, houve um crescimento da participação feminina. Tal fenômeno é explicado por uma combinação de fatores: o avanço da industrialização, o processo de urbanização e a queda das taxas de fecundidade. Para o entendimento das alterações familiares das últimas décadas, sem dúvida, o acesso da mulher ao mercado de trabalho exerce um papel primordial. Em decorrência disso, a estrutura familiar sofre as seguintes consequências: seu tamanho (pelo comportamento da fecundidade), sua hierarquia interna (uma maior presença da mulher como provedora), e a tendência à desintegração dos laços familiares (mais autonomia da mulher).

0 aumento da esperança de vida ao nascer combinado à queda do nível geral de fecundidade resultam no aumento da população idosa. 0 envelhecimento populacional é, hoje, um fenômeno mundial resultante, além da queda do número de filhos, da redução da mortalidade nas idades avançadas. A longevidade tem proporcionado a convivência intergeracional, encontrando-se até quatro gerações em uma mesma residência. Em contrapartida, esse fenômeno também tem trazido à tona a condição de muitos idosos sem o suporte familiar e em condição de vulnerabilidade social.

Para Villa (2012), recentemente, as famílias são formadas por diversas estruturas: casais que já tiveram outros casamentos, pessoas que vivem só, pais com filhos adotivos, mães solteiras com seus filhos, casais que não possuem filhos, uniões homoafetivas, avós com netos, 
famílias expandidas, dentre outras. De acordo com a autora, os valores tradicionais associados à família, apoiados no princípio que atrelava a fatores como sexualidade, reprodução, casamento e manutenção da herança, passaram gradativamente a ser transformados na sociedade contemporânea. Não cabe mais denominar família apenas por aquela formada a partir do casamento entre homem e mulher.

Em suma, diante desse cenário, verifica-se que os processos apresentados transformaram a conformação e a manutenção dos laços sociais primários na sociedade contemporânea. De certa maneira, é possível afirmar que, hoje, sob a perspectiva de Bauman (2001; 2004), Castel (1998a) e Lipovetsky (2005a), esses laços estão mais frágeis, o que gera maior sentimento de insegurança nos indivíduos contemporâneos.

\section{c) Estigma}

Para essa definição, utilizaremos os conceitos emitidos pelo sociólogo Goffman (1978, p. 11), que faz referência ao uso da palavra estigma pelos gregos, definida como "[...] sinais corporais com os quais se procurava evidenciar alguma coisa de extraordinário ou mau sobre o status moral de quem a apresentava”. Segundo o autor, “[...] a sociedade estabelece os meios de categorizar os indivíduos e os atributos considerados comuns, aceitáveis e naturais dentro de cada uma dessas categorias" (ibidem, p. 12). Criam-se categorias e grupos aos quais cada um pertence e, assim, formam-se as identidades sociais.

Segundo Goffman (1978), o estigma é um atributo menos desejável que torna um indivíduo diferente, de 
maneira que os ditos normais deixam de considerá-lo criatura comum, reduzindo-o a uma pessoa estragada e diminuída. Tal característica é um estigma, especialmente quando o seu efeito de descrédito é muito grande algumas vezes, ele também é considerado um defeito, uma fraqueza, uma desvantagem - e constitui uma discrepância específica entre a identidade social virtual e a identidade social real. Sendo assim, a identidade real é o conjunto de atributos que uma pessoa prova ter, em contrapartida, a identidade virtual é o conjunto de atributos impostos pelos ditos normais a tal pessoa; é um estereótipo. Este último, portanto, embutirá um descrédito, formando o que o autor chamou de identidade social deteriorada. "O termo estigma, portanto, será usado em referência a um atributo profundamente depreciativo [...]" (GOFFMAN, 1978, p. 13).

Goffman (1978) afirma que o estigma pode ocorrer devido a três circunstâncias: abominações do corpo, como as diversas deformidades físicas; culpa de caráter individual, como vaidade, desonestidade; e estigmas de raças, tribos, nação e religião. 0 sujeito estigmatizado tem sua capacidade de ação delimitada pela sociedade, que indica o quanto de perigoso pode ele representar socialmente. 0 autor diz que a intensidade de visibilização das marcas do indivíduo estigmatizado dá o grau de dificuldades de reversão de sua imagem projetada e diferenciada pelos padrões aceitos de comportamento social.

Em suma, o estigma é uma construção social que delimita categorias e estereótipos considerados padrões, segundo as normas sociais vigentes. 0 estigma dificulta a formação de laços sociais e o acesso ao mercado de trabalho, provocando o isolamento. 


\section{TIPOLOGA DA EXCLUSÃO SOCAAL}

Explicitados os eixos que compõem a categoria exclusão social, cabe afirmar que é a presença dos três eixos, em conjunto, que ratifica o processo de exclusão social. A presença de um ou de dois evidencia graus de vulnerabilidade. 0 que não é menos importante, pois a presença desses pode levar à inserção em outros eixos e, assim, à exclusão. Dessa maneira, afirmamos aqui existirem três tipos de indivíduos em vulnerabilidade e um excluído.

0 primeiro indivíduo em vulnerabilidade, que chamaremos de economicamente inativo, está inserido na dimensão de precarização do trabalho. Trata-se das pessoas que estão permanentemente ou temporariamente excluídas do mercado de trabalho e sem alguma fonte de renda, direta ou indiretamente. Essa dimensão as impossibilita, em consequência, ao acesso ao consumo, que é, como vimos no primeiro capítulo deste livro, um dos elementos primordiais da sociedade contemporânea. Segundo Bauman (2001) e Lipovetsky (2005a), a inclusão na sociedade contemporânea ocorre através do consumo, o que, na realidade, não se caracteriza por uma verdadeira inclusão, mas dá, sim, uma falsa sensação de ser parte dessa sociedade por meio da possibilidade de adquirir um objeto de consumo, construindo, assim, sua identidade social e aproximando-se dos que também possuem o mesmo objeto.

O segundo indivíduo em vulnerabilidade, o solitário, está inserido na dimensão da precarização da sociabilidade primária. Trata-se dos que não possuem suporte social e relações que o façam sentir-se parte integrante de 
um grupo. Frente ao processo de individualização, essa dimensão está cada vez mais presente na sociedade contemporânea. Tal fenômeno faz com que cada vez mais sejam necessárias políticas públicas que supram essa dimensão com a assistência do Estado.

0 terceiro indivíduo em vulnerabilidade é o estereotipado, que está inserido na dimensão do estigma. Trata-se dos que possuem alguma característica indesejada socialmente. São indivíduos rotulados, que sofrem preconceitos e, portanto, sofrem para serem aceitos na sociedade. Para alguns casos, há políticas de inclusão, como nos casos dos negros, índios, deficientes, sujeitos em sofrimento psíquico, dentre outros. Entretanto, mesmo com políticas públicas a eles dirigidas, sem a alteração do imaginário social, eles não conseguem, de fato, ser efetivamente aceitos.

Conforme já exposto, um indivíduo pode possuir mais de uma dessas dimensões, o que agravaria o seu grau de vulnerabilidade. Entretanto, se possuir as três, ele se encaixaria no que denominamos de excluído. Aqui, encaixam-se os indivíduos em situação de rua, idosos abandonados nos asilos, moradores dos hospitais psiquiátricos, dentre outros. São os indivíduos em grau extremos de vulnerabilidade.

Por fim, pode-se afirmar que são múltiplas as causas que levam um indivíduo à vulnerabilidade social e, em casos mais graves, à sua exclusão social.

Conclui-se, assim, que a inclusão social é uma ação política pela qual uma instituição, que pode ser pública (Estado), organização da sociedade civil e privada, visa alterar um dado estado de exclusão social. Se ela visa alterar a exclusão - que é composta de três dimensões 
desencadeadoras (precarização do trabalho, precarização da sociabilidade primária e estigma) -, temos como pressuposto que essa ação deve, então, atacar essas causas para, assim, pôr fim ao estado de exclusão desse sujeito ou grupo excluído.

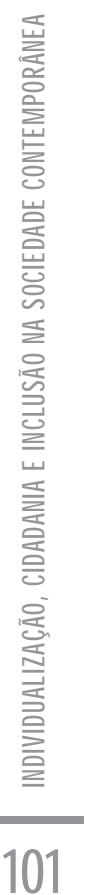

